\title{
Thin-film flip-chip UVB LEDs realized by electrochemical etching ${ }^{\circledR}$
}

Cite as: Appl. Phys. Lett. 116, 121101 (2020); https://doi.org/10.1063/1.5143297

Submitted: 21 December 2019 . Accepted: 11 March 2020 . Published Online: 24 March 2020

Michael A. Bergmann (D), Johannes Enslin (D), Filip Hjort (D), Tim Wernicke (D), Michael KneissI (D), and Åsa Haglund (D)

\section{COLLECTIONS}

\section{ARTICLES YOU MAY BE INTERESTED IN}

On-wafer fabrication of etched-mirror UV-C laser diodes with the ALD-deposited DBR Applied Physics Letters 116, 122101 (2020); https://doi.org/10.1063/1.5145017

Modulation of the two-dimensional electron gas channel in flexible AlGaN/GaN high-electronmobility transistors by mechanical bending

Applied Physics Letters 116, 123501 (2020); https://doi.org/10.1063/1.5142546

A perspective on blue TADF materials based on carbazole-benzonitrile derivatives for efficient and stable OLEDs

Applied Physics Letters 116, 120503 (2020); https://doi.org/10.1063/1.5143501

\section{Lock-in Amplifiers up to $600 \mathrm{MHz}$}



\title{
Thin-film flip-chip UVB LEDs realized by electrochemical etching ${ }^{\circledR}$
}

\author{
Cite as: Appl. Phys. Lett. 116, 121101 (2020); doi: 10.1063/1.5143297 \\ Submitted: 21 December 2019 - Accepted: 11 March 2020 . \\ Published Online: 24 March 2020
}

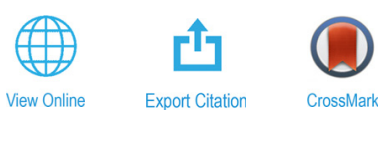

\author{
Michael A. Bergmann, ${ }^{1, a)}$ (D) Johannes Enslin, ${ }^{2}$ (D) Filip Hjort, ${ }^{1}$ (D) Tim Wernicke, ${ }^{2}$ (D) Michael Kneissl, ${ }^{2}$ \\ and Åsa Haglund'
}

\begin{abstract}
AFFILIATIONS
'Department of Microtechnology and Nanoscience, Chalmers University of Technology, 41296 Gothenburg, Sweden

${ }^{2}$ Institute of Solid State Physics, Technische Universität Berlin, 10623 Berlin, Germany
\end{abstract}

${ }^{a)}$ Author to whom correspondence should be addressed: michael.bergmann@chalmers.se

\begin{abstract}
We demonstrate a thin-film flip-chip (TFFC) light-emitting diode (LED) emitting in the ultraviolet B (UVB) at $311 \mathrm{~nm}$, where substrate removal has been achieved by electrochemical etching of a sacrificial $\mathrm{Al}_{0.37} \mathrm{Ga}_{0.63} \mathrm{~N}$ layer. The electroluminescence spectrum of the TFFC LED corresponds well to the as-grown LED structure, showing no sign of degradation of structural and optical properties by electrochemical etching. This is achieved by a proper epitaxial design of the sacrificial layer and the etch stop layers in relation to the LED structure and the electrochemical etch conditions. Enabling a TFFC UV LED is an important step toward improving the light extraction efficiency that limits the power conversion efficiency in AlGaN-based LEDs.
\end{abstract}

(C) 2020 Author(s). All article content, except where otherwise noted, is licensed under a Creative Commons Attribution (CC BY) license (http:// creativecommons.org/licenses/by/4.0/). https://doi.org/10.1063/1.5143297

Ultraviolet (UV) light sources are used in a number of applications such as water disinfection, UV curing, and phototherapy. ${ }^{1} \mathrm{UV}$ light-emitting diodes (LEDs) are expected to replace conventional UV light sources like mercury gas discharge lamps due to their small form factor, robustness, environmentally friendly materials, and selectable emission wavelength. ${ }^{2}$ However, the poor power conversion efficiency of UV LEDs below 10\% for wavelengths shorter than $350 \mathrm{~nm}$, see Ref. 2, strongly limits their widespread use.

One of the major factors limiting the power conversion efficiency is the light extraction efficiency (LEE), ${ }^{2}$ which can be improved by a thin-film flip-chip (TFFC) design. Aoshima et al. ${ }^{3}$ have fabricated TFFC LEDs emitting in the ultraviolet A (UVA) and achieved an improvement in the LEE of $1.7 \times$ compared to a flip-chip (FC) design. Sung et al. ${ }^{4}$ demonstrated an improvement in the LEE for ultraviolet C (UVC) LEDs of $1.31 \times$ for a TFFC design compared to a FC design. In both the cases, a major factor for the improvement was the surface roughening to reduce total internal reflection, which was made possible by removing the substrate. The influence of the surface roughening on the LEE for TFFC LEDs emitting in the UVA and UVC has also been reported by other groups. ${ }^{5-8}$

Despite these demonstrations using laser lift-off (LLO) for the fabrication of UV TFFC LEDs, ${ }^{3-5,7,8}$ substrate removal remains challenging. LLO is a standard process for GaN-based LEDs emitting in the blue, ${ }^{9}$ but for AlGaN-based LEDs, the thermal decomposition of $\mathrm{AlGaN}$ yields aluminum residues that are more rigid than Ga residues as in the case of $\mathrm{GaN} .{ }^{10}$ In addition, the substrate removal by LLO can lead to cracking of the strained epitaxial layers due to the thermal shock that is enhanced since $\mathrm{AlGaN}$ requires higher temperature to decompose. ${ }^{10,11}$ To circumvent these issues, a GaN interlayer has been used for LLO, which was completely removed afterwards using dry etching to avoid optical absorption of the UV emission from the LED. ${ }^{12}$ The integration of such a non-lattice matched layer can lead to dislocation generation, relaxation, and roughness of the layers grown on top, ${ }^{13,14}$ which strongly limits the aluminum contents and layer thicknesses that can be used for the LED structure grown on top.

An alternative to thermal decomposition of AlGaN for the substrate removal is doping-selective electrochemical etching. This has been used to laterally etch $\mathrm{GaN}$ and low $\mathrm{Al}$ composition $\mathrm{AlGaN}$ layers for the fabrication of thin-film LEDs emitting in the blue regime, ${ }^{15-17}$ transfer of III-nitride membranes, ${ }^{18-21}$ and fabrication of photonic crystal structures. ${ }^{22}$ Electrochemical etching has low requirements on the processing equipment and can be accomplished using standard electroplating tools. This is in contrast to photoelectrochemical etching that is based on bandgap-selective absorption. ${ }^{23,24}$ Therefore, photoelectrochemical etching requires a more complex setup with a wavelength-specific homogeneous illumination. Thus, for photoelectrochemical etching, the 
sacrificial layer and device layers have to be designed with respect not only to selective current flows as in electrochemical etching but also to selective optical absorption, which, in most cases, involves the use of non-lattice matched sacrificial layers.

Recently, we have demonstrated that electrochemical etching can be applied to etch $\mathrm{AlGaN}$ with an $\mathrm{Al}$ content up to $50 \%{ }^{25}$ This opens up the possibility to incorporate a lattice matched sacrificial AlGaN layer that can be selectively removed to realize TFFC UV LEDs of high quality. In this work, we demonstrate a TFFC ultraviolet B (UVB) LED using this method.

The epitaxial layer structure of the UVB LED including the layers required for the electrochemical etching is shown in Fig. 1. The structure was grown in a $3 \times 2^{\prime \prime}$ close-coupled showerhead reactor using the standard precursors trimethylaluminium (TMAl), trimethylgallium (TMGa), trimethylindium (TMIn), and ammonia $\left(\mathrm{NH}_{3}\right)$ with hydrogen or nitrogen as the carrier gas. Silane $\left(\mathrm{SiH}_{4}\right)$ was used as a n-dopant source and cyclopentadienylmagnesium $\left(\mathrm{Cp}_{2} \mathrm{Mg}\right)$ as a p-dopant. First, an AlN/AlGaN-superlattice for strain management was grown on an AlN/sapphire substrate ${ }^{13}$ provided by the Ferdinand-Braun-Institut. This was followed by a $4 \mu \mathrm{m}$ thick relaxed silicon doped $\mathrm{Al}_{0.5} \mathrm{Ga}_{0.5} \mathrm{~N}$-layer with a $\mathrm{Si}$ concentration of $2 \times 10^{18} \mathrm{~cm}^{-3}$ to complete the quasi-substrate. ${ }^{14,26}$ After that, a $130 \mathrm{~nm}$ thick $\mathrm{Al}_{0.37} \mathrm{Ga}_{0.63} \mathrm{~N}: \mathrm{Si}$ sacrificial layer with a Si-concentration of $2 \times 10^{19} \mathrm{~cm}^{-3}$ was sandwiched between two $240 \mathrm{~nm}$ thick $\mathrm{Al}_{0.5} \mathrm{Ga}_{0.5} \mathrm{~N}$ :Si etch-stop layers with a reduced Si-concentration of $0.5 \times 10^{18} \mathrm{~cm}^{-3}$. On top of that, the $\mathrm{Al}_{0.5} \mathrm{Ga}_{0.5} \mathrm{~N}$ :Si current spreading layer for the LED was grown. This was followed by a threefold InAlGaN MQW active region emitting at $311 \mathrm{~nm}$, an $\mathrm{Al}_{0.75} \mathrm{Ga}_{0.25} \mathrm{~N}$ electron blocking layer, and a Mg-doped $\mathrm{AlGaN} / \mathrm{AlGaN}$ superlattice with an average $\mathrm{Al}$ concentration of $50 \%$ and a $\mathrm{Mg}$ concentration of $7 \times 10^{19} \mathrm{~cm}^{-3}$. Finally, the structure was capped by a $20 \mathrm{~nm}$ thick GaN:Mg contact layer. The threading dislocation density of the epitaxial layers is around $3 \times 10^{9} \mathrm{~cm}^{-2}$.

The process flow for the TFFC LEDs is summarized in Figs. 2(a)-2(d), 3(a), and 3(b). The fabrication started with the definition of the LED's emission area. A circular mesa with a diameter of $80 \mu \mathrm{m}$ was defined by standard photolithography and chlorine-based reactive ion etching into the $\mathrm{n}$-doped $\mathrm{Al}_{0.5} \mathrm{Ga}_{0.5} \mathrm{~N}$ current spreading layer of the LED. An additional dry etching step into the bottom $\mathrm{n}^{-}$doped $\mathrm{Al}_{0.5} \mathrm{Ga}_{0.5} \mathrm{~N}$-layer, used as the etch stop layer, was performed to expose the $\mathrm{n}$-doped $\mathrm{Al}_{0.37} \mathrm{Ga}_{0.63} \mathrm{~N}$ sacrificial layer. This etch also

\begin{tabular}{|c|c|c|c|}
\hline $20 \mathrm{~nm}$ & p-GaN & \multirow{3}{*}{$\begin{array}{l}\mathrm{EBL} \\
\text { InAIGaN/AIGaN } \\
\text { MQWs }\end{array}$} & \multirow{3}{*}{$\begin{array}{l}\text { LED } \\
\text { structure }\end{array}$} \\
\hline $200 \mathrm{~nm}$ & p-AIGaN SL & & \\
\hline $730 \mathrm{~nm}$ & $\mathrm{n}-\mathrm{Al}_{0.5} \mathrm{Ga}_{0.5} \mathrm{~N}$ & & \\
\hline $240 \mathrm{~nm}$ & $\mathrm{n}-\mathrm{Al}_{0.5} \mathrm{Ga}_{0.5} \mathrm{~N}$ & \multirow{4}{*}{$\begin{array}{l}\text { Etch block } \\
\text { Sacrificial layer } \\
\text { Etch block } \\
\text { Current spreader }\end{array}$} & \multirow{4}{*}{$\begin{array}{l}\text { Release } \\
\text { structure }\end{array}$} \\
\hline $130 \mathrm{~nm}$ & $\mathrm{n}^{+}-\mathrm{Al}_{0.37} \mathrm{Ga}_{0.63} \mathrm{~N}$ & & \\
\hline $240 \mathrm{~nm}$ & $\mathrm{n}^{-}-\mathrm{Al}_{0.5} \mathrm{Ga}_{0.5} \mathrm{~N}$ & & \\
\hline $4.25 \mu \mathrm{m}$ & $\mathrm{n}-\mathrm{Al}_{0.5} \mathrm{Ga}_{0.5} \mathrm{~N}$ & & \\
\hline & Buffer layer & & \\
\hline & $\begin{array}{r}\text { AIN/Sapphire } \\
\text { template }\end{array}$ & & \\
\hline
\end{tabular}

FIG. 1. Epitaxial structure of the UVB LED and the layers required for substrate removal by electrochemical etching.


FIG. 2. (a) Sample structure after the p-side processing, (b) three-electrode setup for electrochemical etching, (c) sacrificial layer removal, and (d) current flow during electrochemical etching.

defined the area to be lifted-off. The contact pad for the electrochemical etching consisting of $\mathrm{Ti} / \mathrm{Al} / \mathrm{Ti} / \mathrm{Au}(20 / 80 / 40 / 100 \mathrm{~nm})$ was deposited on one end of the sample using electron-beam evaporation and annealed for $1 \mathrm{~min}$ at $900^{\circ} \mathrm{C}$ in a $\mathrm{N}_{2}$ atmosphere. A $50 \mathrm{~nm} \mathrm{Pd}$ $\mathrm{p}$-contact was then evaporated on top of the double mesa and annealed for $1 \mathrm{~min}$ at $550{ }^{\circ} \mathrm{C}$ in the $\mathrm{N}_{2}$ atmosphere. To protect the doped epitaxial LED layers from parasitic etching during the electrochemical process, $\mathrm{a} \mathrm{SiO}_{2}$ layer was deposited on the sample using sputtering. In a first dry etching step, the $\mathrm{SiO}_{2}$ layer was etched down beside the mesa to $300 \mathrm{~nm}$ to obtain a thinner tether layer, while its full thickness of $1 \mu \mathrm{m}$ was kept on top of the mesa to create a larger distance between the mesa top and the sample surface to facilitate bonding. In a second dry etching step, the $\mathrm{SiO}_{2}$ layer was opened up at three different locations: on top of the mesas to access the p-contact layer, at one point at the mesa edge to expose the sacrificial layer, and on the n-contact pad used for electrochemical etching. Subsequently, a Ti/Au pad for bonding and contacting was deposited on top of the mesa by tilted e-beam evaporation. The device structure after the $\mathrm{p}$-side processing is shown in Fig. 2(a). 

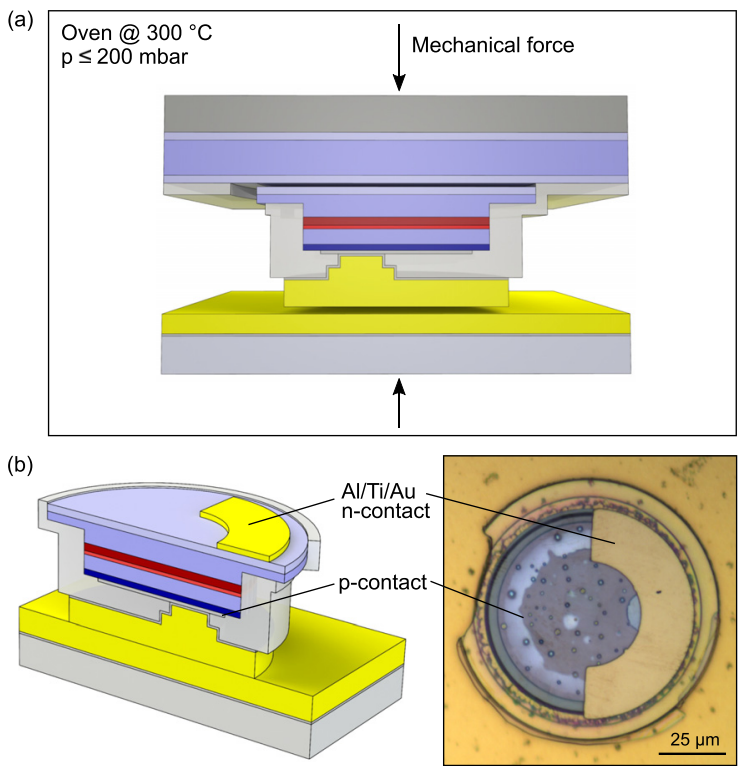

FIG. 3. (a) Flip-chip bonding in the vacuum oven and (b) schematic and optical microscope image of the thin-flip flip-chip LED before the $n$-contact annealing.

To release the LEDs from the substrate, the sacrificial layer was laterally removed using electrochemical etching. In this step, the sample was immersed in $0.3 \mathrm{M}$ nitric acid and electrically connected to a Biologic potentiostat in a three-electrode setup, see Fig. 2(b). To prevent parasitic etching, the electrical connection to the sample was protected from the electrolyte. A graphite rod was used as the counter electrode to drive the required current through the sample in order to achieve the set potential on the sample relative to the $\mathrm{Ag} /$ $\mathrm{AgCl}$ reference electrode. The electrolyte was stirred with a magnetic stir bar, and etching was conducted at room temperature with no intentional illumination. An etching voltage of $25 \mathrm{~V}$ vs the $\mathrm{Ag} / \mathrm{AgCl}$ reference electrode was chosen to achieve complete removal of the $\mathrm{n}$-doped $\mathrm{Al}_{0.37} \mathrm{Ga}_{0.63} \mathrm{~N}$ sacrificial layer, as shown in Ref. 25, and still to prevent etching of the etch stop and doped device layers. The lower $\mathrm{Al}$ composition and higher doping of the sacrificial layer relative to the etch block layers on both the sides confine the etching to only the sacrificial layer. Because the sacrificial layer is only exposed to the electrolyte at one side of the mesa, the etching proceeds across the mesa from one direction in one step, see Fig. 2(c). The $\mathrm{SiO}_{2}$ sidewall protection further ensures a good current flow throughout the full electrochemical etch process and constant etching conditions, see Figs. 2(c) and 2(d). After the etching process, the sample was immersed in de-ionized water for $1 \mathrm{~min}$ to dissolve acid residues and then immersed in isopropanol to reduce any force on the membrane when allowed to dry in air. The underetched LEDs were held in place by the $\mathrm{SiO}_{2}$ tethers. To flip-chip bond the underetched thin-film LEDs, thermocompression bonding was used. Prior to the bonding, the bonding metal surfaces on both the LED devices and the Si carrier chip with a Ti/Au $(10 / 300 \mathrm{~nm})$ bonding layer were cleaned by UV-ozone. Subsequently, the chips were pressed together using an in-house designed stainless-steel compression fixture that was placed in an oven at $300^{\circ} \mathrm{C}$ for $2 \mathrm{~h}$, see Fig. 3(a). The bonding pressure on the bond pad area was set to $50 \mathrm{MPa}$. To reduce air pockets, the oven was evacuated to a pressure $\leq 200 \mathrm{mbar}$. During the bonding process, the $\mathrm{SiO}_{2}$ tethers break and the thin-film LEDs are transferred to the Si carrier.

The device process was completed by the formation of an $\mathrm{Al} / \mathrm{Ti} /$ $\mathrm{Au}(100 / 20 / 30 \mathrm{~nm}) \mathrm{n}$-contact on top of the mesa as shown in the optical microscope image in Fig. 3(b). An annealing temperature of $550{ }^{\circ} \mathrm{C}$ for the $\mathrm{n}$-contact was chosen to minimize the degradation of the p-contact. The cross-sectional SEM image of the final TFFC LED achieved by a focused-ion-beam-cut shows well-defined device layers and indicates a smoothly etched surface as seen in Fig. 4. Moreover, the device layers show no indication of being porosified by the electrochemical etch process. An improper combination of doping levels, thicknesses, and $\mathrm{Al}$ compositions of the LED layers and etch stop layer in relation to the sacrificial layer and etch voltage would result in undesired porosification with pore diameters of $50 \mathrm{~nm}-100 \mathrm{~nm},{ }^{27}$ which would clearly be visible in the cross-sectional SEM image. In addition, time-resolved photoluminescence (PL) measurements yielded similar PL decay times of $340 \pm 30$ ps at room temperature for the quantum wells in the as-grown LEDs and in the TFFC LEDs, indicating no degradation of the active region. ${ }^{25}$

Figure 5 shows the electroluminescence spectrum at room temperature of the TFFC LED at a current density of $0.8 \mathrm{~A} / \mathrm{cm}^{2}$ with a single emission peak at $311 \mathrm{~nm}$. This corresponds well to the electroluminescence peak wavelength of $312 \mathrm{~nm}$ of the as-grown LED structure that was contacted using an In-dot, for which the emission was collected through the sapphire substrate. The full width at half maximum for the TFFC LED is $9 \mathrm{~nm}$ and $11 \mathrm{~nm}$ for the as-grown LED structure.

Figure 6 shows the voltage and optical output power as a function of current density for a TFFC LED with a p-contact diameter of $68 \mu \mathrm{m}$. The electroluminescence was measured using a broad-area UV-enhanced Si photodiode S2281 from Hamamatsu. The graph shows a linear output power vs current density, as expected for an LED. This proof-of-principle device is not optimized for high light extraction efficiency, and therefore, the optical output power that is in the low $\mu \mathrm{W}$ regime is stated in arbitrary units. A homogeneous current injection across the p-contact area is assumed when calculating the current density. However, near-field imaging of the spontaneous emission at a current of $0.2 \mathrm{~mA}$ [see Fig. 7(b)] shows that this is an underestimation of the current density due to a non-homogeneous

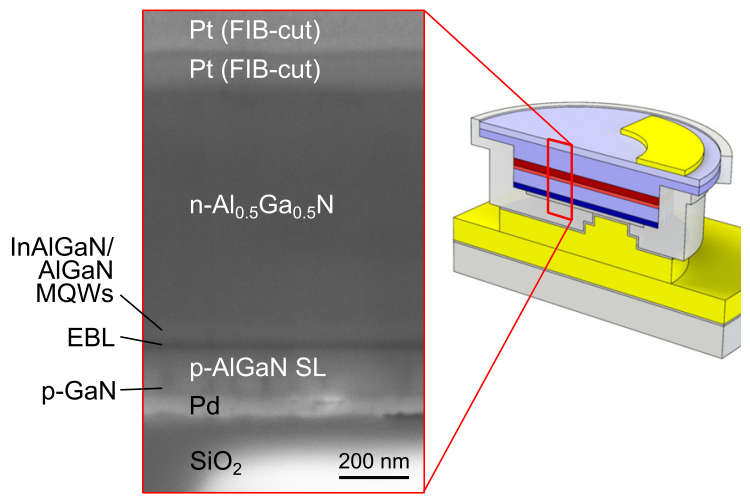

FIG. 4. Cross-sectional SEM image of the transferred LED structure. 


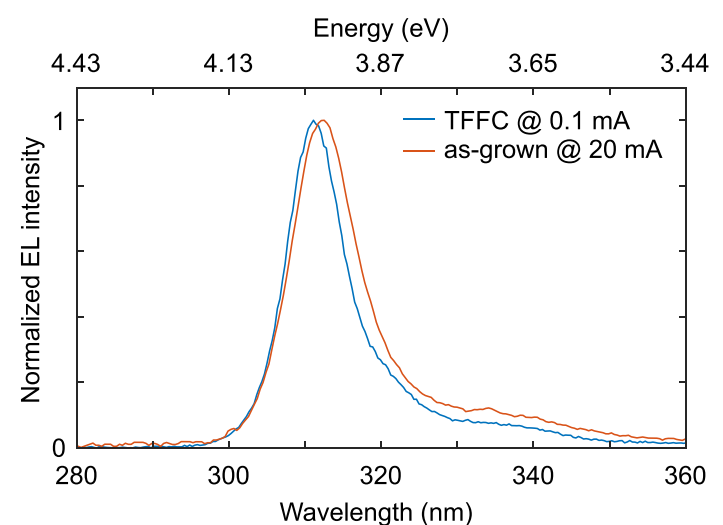

FIG. 5. Normalized electroluminescence spectrum of the as-grown epitaxy and the TFFC LED at room temperature.

current injection caused by a degraded p-contact. The voltage vs current density reveals a high differential resistance of the LED of about $63 \mathrm{k} \Omega$ at $3 \mathrm{~A} / \mathrm{cm}^{2}$. This is attributed to a highly resistive $\mathrm{n}$-contact as the fabrication process was not optimized for the N-polar backside with low n-type doping, additionally hindered by the limited annealing temperature to avoid damaging of the LED and possible degradation of the p-contact. A different process flow, where the $n$-contact can be annealed before the p-contact, could solve these issues.

In conclusion, we have demonstrated a thin-film flip-chip UVB LED where the substrate removal was achieved by lateral electrochemical etching of an AlGaN sacrificial layer. The LED structure was not structurally or optically affected by the substrate removal technique, through a proper design of the sacrificial layer (doping level, thickness, and $\mathrm{Al}$ composition) in relation to the etch stop layer and the device layers, and choice of the etch voltage. The electroluminescence spectrum shows a single peak emission at $311 \mathrm{~nm}$ for the thin-film flipchip LED, which corresponds to the emission wavelength of the asgrown LED structure, indicating no significant strain being introduced or released in the thin-film flip-chip process. The high series resistance of the LED was attributed to high contact resistance caused by a nonoptimized annealing temperature and n-contacts on low-doped, $\mathrm{N}$-polar AlGaN. An alternative process flow, where the n-contact is

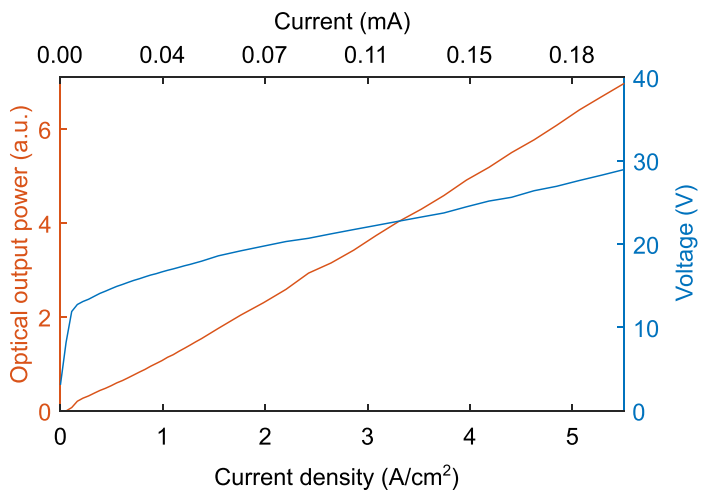

FIG. 6. P-I-V characteristics of the TFFC LED. (a)

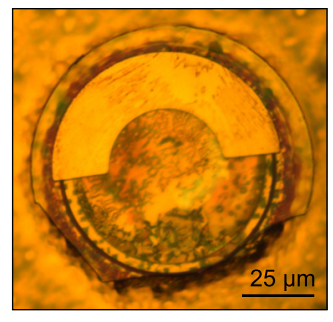

(b)



FIG. 7. (a) Optical microscope image of the TFFC LED and (b) spatially resolved near-field emission at a current of $0.2 \mathrm{~mA}$. Electroluminescence intensity is on a linear scale.

annealed before the p-contact, should solve this issue. The developed thin-film process is not limited to UVB LEDs but can also be applied to deep-UV LEDs and other devices such as UV vertical-cavity surface-emitting lasers that benefit from the integration of high-quality III-nitride device layers with other structures such as dielectric distributed Bragg reflectors.

This work was performed in part at Myfab Chalmers. This project was financially supported by the Swedish Foundation for Strategic Research, the Swedish Research Council (Project Nos. 2016-04686 and 2018-00295), and the Deutsche Forschungsgemeinschaft (DFG) within the Collaborative Research Center "Semiconductor Nanophotonics" (SFB 787).

\section{REFERENCES}

${ }^{1}$ III-Nitride Ultraviolet Emitters, Springer Series in Materials Science Vol. 227, edited by M. Kneissl and J. Rass (Springer International Publishing, 2016).

${ }^{2}$ M. Kneissl, T.-Y. Seong, J. Han, and H. Amano, "The emergence and prospects of deep-ultraviolet light-emitting diode technologies," Nat. Photonics 13, 233-244 (2019).

${ }^{3}$ H. Aoshima, K. Takeda, K. Takehara, S. Ito, M. Mori, M. Iwaya, T. Takeuchi, S. Kamiyama, I. Akasaki, and H. Amano, "Laser lift-off of AlN/sapphire for UV light-emitting diodes,” Phys. Status Solidi C 9, 753-756 (2012).

${ }^{4}$ Y. J. Sung, M.-S. Kim, H. Kim, S. Choi, Y. H. Kim, M.-H. Jung, R.-J. Choi, Y.T. Moon, J.-T. Oh, H.-H. Jeong, and G. Y. Yeom, "Light extraction enhancement of AlGaN-based vertical type deep-ultraviolet light-emitting-diodes by using highly reflective ITO/Al electrode and surface roughening," Opt. Express 27, 29930-29937 (2019).

${ }^{5}$ C. E. Leez, B. S. Cheng, Y. C. Lee, H. C. Kuo, T. C. Lu, and S. C. Wang, "Output power enhancement of vertical-injection ultraviolet light-emitting diodes by GaN-free and surface roughness structures," Electrochem. SolidState Lett. 12, H44-H46 (2009).

${ }^{6}$ B. K. SaifAddin, A. Almogbel, C. J. Zollner, H. Foronda, A. Alyamani, A. Albadri, M. Iza, S. Nakamura, S. P. DenBaars, and J. S. Speck, "Fabrication technology for high light-extraction ultraviolet thin-film flip-chip (UV TFFC) LEDs grown on SiC," Semicond. Sci. Technol. 34, 035007 (2019).

${ }^{7}$ L. Zhou, J. E. Epler, M. R. Krames, W. Goetz, M. Gherasimova, Z. Ren, J. Han, M. Kneissl, and N. M. Johnson, "Vertical injection thin-film AlGaN/AlGaN multiple-quantum-well deep ultraviolet light-emitting diodes," Appl. Phys. Lett. 89, 241113 (2006).

${ }^{8}$ M. Lachab, F. Asif, B. Zhang, I. Ahmad, A. Heidari, Q. Fareed, V. Adivarahan, and A. Khan, "Enhancement of light extraction efficiency in sub-300 nm nitride thin-film flip-chip light-emitting diodes," Solid-State Electron. 89, 156-160 (2013).

${ }^{9}$ M. K. Kelly, O. Ambacher, R. Dimitrov, R. Handschuh, and M. Stutzmann, "Optical process for liftoff of group III-nitride films," Phys. Status Solidi A 159, R3-R4 (1997). 
${ }^{10}$ H. K. Cho, O. Krüger, A. Külberg, J. Rass, U. Zeimer, T. Kolbe, A. Knauer, S. Einfeldt, M. Weyers, and M. Kneissl, "Chip design for thin-film deep ultraviolet LEDs fabricated by laser lift-off of the sapphire substrate," Semicond. Sci. Technol. 32, 12LT01 (2017).

${ }^{11}$ M. Arita, S. Kako, S. Iwamoto, and Y. Arakawa, "Fabrication of AlGaN twodimensional photonic crystal nanocavities by selective thermal decomposition of GaN," Appl. Phys. Express 5, 126502 (2012).

${ }^{12}$ J.-T. Oh, Y.-T. Moon, D.-S. Kang, C.-K. Park, J.-W. Han, M.-H. Jung, Y.-J. Sung, H.-H. Jeong, J.-O. Song, and T.-Y. Seong, "High efficiency ultraviolet GaN-based vertical light emitting diodes on 6-inch sapphire substrate using exsitu sputtered AlN nucleation layer," Opt. Express 26, 5111-5117 (2018).

${ }^{13}$ O. Reentilä, F. Brunner, A. Knauer, A. Mogilatenko, W. Neumann, H. Protzmann, M. Heuken, M. Kneissl, M. Weyers, and G. Tränkle, "Effect of the AIN nucleation layer growth on AIN material quality," J. Cryst. Growth 310, 4932-4934 (2008).

${ }^{14}$ J. Enslin, F. Mehnke, A. Mogilatenko, K. Bellmann, M. Guttmann, C. Kuhn, J. Rass, N. Lobo-Ploch, T. Wernicke, M. Weyers, and M. Kneissl, "Metamorphic $\mathrm{Al}_{0.5} \mathrm{Ga}_{0.5} \mathrm{~N}: \mathrm{Si}$ on AlN/sapphire for the growth of UVB LEDs," J. Cryst. Growth 464, 185-189 (2017).

${ }^{15}$ K.-C. Wu, K.-P. Huang, P.-F. Cheng, W.-P. Tseng, Y.-C. Huang, R.-H. Jiang, J.H. Wang, B.-C. Shieh, C.-F. Lai, and C.-F. Lin, "Fabricated InGaN membranes through a wet lateral etching process,” Appl. Phys. Express 6, 086501 (2013).

${ }^{16}$ L. Feng, Y. Li, H. Xiong, S. Wang, J. Wang, W. Ding, Y. Zhang, and F. Yun, "Freestanding GaN-based light-emitting diode membranes on $\mathrm{Y}_{3} \mathrm{Al}_{5} \mathrm{O}_{12}: \mathrm{Ce}^{3+}$ crystal phosphor plate for efficient white light emission," Appl. Phys. Express 9 , 081003 (2016)

${ }^{17}$ S. H. Park, G. Yuan, D. Chen, K. Xiong, J. Song, B. Leung, and J. Han, "Wide bandgap III-nitride nanomembranes for optoelectronic applications," Nano Lett. 14, 4293-4298 (2014).
${ }^{18}$ K. Xiong, S. H. Park, J. Song, G. Yuan, D. Chen, B. Leung, and J. Han, “Single crystal gallium nitride nanomembrane photoconductor and field effect transistor," Adv. Funct. Mater. 24, 6503-6508 (2014).

${ }^{19}$ J.-H. Kang, D. K. Jeong, and S.-W. Ryu, "Transparent, flexible piezoelectric nanogenerator based on GaN membrane using electrochemical lift-off," ACS Appl. Mater. Interfaces 9, 10637-10642 (2017).

${ }^{20}$ A. W. Bruch, K. Xiong, H. Jung, X. Guo, C. Zhang, J. Han, and H. X. Tang, "Electrochemically sliced low loss AlGaN optical microresonators," Appl. Phys. Lett. 110, 021111 (2017).

${ }^{21}$ T.-H. Chang, K. Xiong, S. H. Park, G. Yuan, Z. Ma, and J. Han, "Strain balanced AlGaN/GaN/AlGaN nanomembrane HEMTs,” Sci. Rep. 7, 6360 (2017).

${ }^{22} \mathrm{D}$. Chen and J. Han, "High reflectance membrane-based distributed Bragg reflectors for GaN photonics," Appl. Phys. Lett. 101, 221104 (2012).

${ }^{23}$ P. Visconti, M. A. Reshchikov, K. M. Jones, D. F. Wang, R. Cingolani, H. Morkoç, R. J. Molnar, and D. J. Smith, "Highly selective photoelectrochemical etching of nitride materials for defect investigation and device fabrication," J. Vac. Sci. Technol., B 19, 1328-1333 (2001).

${ }^{24}$ A. R. Stonas, T. Margalith, S. P. DenBaars, L. A. Coldren, and E. L. Hu, "Development of selective lateral photoelectrochemical etching of InGaN/GaN for lift-off applications,” Appl. Phys. Lett. 78, 1945-1947 (2001).

${ }^{25}$ M. A. Bergmann, J. Enslin, R. Yapparov, F. Hjort, B. Wickman, S. Marcinkevičius, T. Wernicke, M. Kneissl, and A. Haglund, "Electrochemical etching of AlGaN for the realization of thin-film devices," Appl. Phys. Lett. 115, 182103 (2019).

${ }^{26}$ A. Mogilatenko, J. Enslin, A. Knauer, F. Mehnke, K. Bellmann, T. Wernicke, M. Weyers, and M. Kneissl, "V-pit to truncated pyramid transition in AlGaNbased heterostructures," Semicond. Sci. Technol. 30, 114010 (2015).

${ }^{27}$ G.-J. Wang, B.-S. Hong, Y.-Y. Chen, Z.-J. Yang, T.-L. Tsai, Y.-S. Lin, and C.-F. Lin, "GaN/AlGaN ultraviolet light-emitting diode with an embedded porousAlGaN distributed Bragg reflector,” Appl. Phys. Express 10, 122102 (2017). 